\title{
Metode Skrining Gizi di Rumah Sakit dengan MST Lebih Efektif dibandingkan SGA
}

\section{Nutrition Screening Method in Hospital with MST is More Effective than SGA}

\author{
Herawati ${ }^{1}$, Triwahyu $S^{2}$, Arief Alamsyah ${ }^{3}$ \\ ${ }^{1}$ Rumah Sakit Umum Daerah Dr. Saiful Anwar Malang \\ ${ }^{2}$ Rumah Sakit Islam Unisma Malang \\ ${ }^{3}$ Program Magister Manajemen Rumah Sakit Fakultas Kedokteran Universitas Brawijaya Malang
}

\begin{abstract}
ABSTRAK
Pelayanan asuhan gizi rawat inap adalah serangkaian kegiatan terorganisir atau terstruktur yang memungkinkan untuk identifikasi kebutuhan dan penyediaan asuhan gizi guna memenuhi kebutuhan pasien. Pelayanan asuhan gizi rawat inap meliputi skrining gizi dan PAGT (Proses Asuhan Gizi Terstandar). Ketepatan pemilihan, kemudahan penggunaan metode skrining gizi dan penerapan PAGT sangat diperlukan guna menunjang pelaksanaan asuhan gizi rawat inap yang lebih berkualitas. Penelitian ini bertujuan memilih metode skrining gizi dan form PAGT yang diterapkan di RSI Unisma Malang yang lebih efektif dan efisien sehingga dapat meningkatkan mutu pelayanan gizi yang optimal sesuai dengan Pedoman Gizi Rumah Sakit (PGRS) Tahun 2013. Dilakukan uji coba penerapan metode skrining gizi dan form PAGT di ruang rawat inap RSI Unisma Malang serta dilakukan evaluasi efektifitas, efisiensi dari penerapan metode skrining gizi dan form PAGT tersebut. Hasilnya adalah peningkatan cakupan jumlah pasien yang terskrining menggunakan metode MST sebesar $34,4 \%$ dibandingkan dengan penggunaan metode SGA. Peningkatan cakupan jumlah pasien yang dilakukan PAGT sebesar $100 \%$ dari pasien yang beresiko tinggi malnutrisi dari yang dilakukan skrining awal. Metode skrining MST dinilai lebih cepat, sederhana, efektif, efisien dan aplikatif. Format PAGT lebih sederhana dan mudah dilakukan di RSI Unisma Malang.
\end{abstract}

Kata Kunci: MST, PAGT, skrining gizi

\section{ABSTRACT}

Inpatient nutritional care is a group of organized activities which allow identifying nutritional need and caring to meet the need of patients. It consists of nutritional screening and Standardized Nutritional Care Process (SNCP). Accurate selection and easy usage of nutrition screening method and application of SNCP were needed to support the implementation of higher quality inpatient nutritional care. This research is aimed to choose the most effective and efficient nutritional care and SNCP form applied in Unisma Islamic Hospital Malang, in order to improve the quality of optimal nutritional service based on Hospital Nutrition Guidelines 2013. Some application trials on nutritional screening method and SNCP form in inpatient units of Unisma Islamic Hospital Malang were conducted, and then evaluation on the effectiveness, efficiency and application of nutritional screening method and SNCP form. The result is a coverage increase in the patient number that were screened by using MST method of 34,4\% compared to SDA method. The increase of covered patient number by using SNCP is $100 \%$ from patient with high risk of malnutrition from the first screening. MST screening method is the quicker, simpler, more effective, more efficient and more applicable. The SNCP Form is need to be simplify in order to carry out in Unisma Islamic Hospital Malang.

Keywords: MST, nutritional screening, PAGT

Jurnal Kedokteran Brawijaya, Vol. 28, Suplemen No. 1, 2014: Herawati. Rumah Sakit Umum Daerah Dr. Saiful Anwar Malang, Jl. Jaksa Agung Suprapto No. 2 Malang Tel. (0341)362101Email:herawati_eq@yahoo.com 


\section{PENDAHULUAN}

Pelayanan gizi rumah sakit adalah pelayanan gizi yang di sesuaikan dengan keadaan pasien berdasarkan keadaan klinis, status gizi dan status metabolisme tubuh (1). Keadaan gizi pasien sangat berpengaruh terhadap keadaan pasien, sering terjadi kondisi pasien semakin buruk karena tidak diperhatikan keadaan gizinya. Pelayanan gizi rawat inap merupakan pelayanan yang dimulai dari proses skrining, diagnosa, dan intervensi gizi (Penyuluhan atau Edukasi dan Konseling Gizi) serta monitoring dan evaluasi gizi. Upaya tersebut bertujuan memberikan pelayan gizi kepada pasien rawat inap agar memperoleh asupan makanan yang sesuai kondisi kesehatannya dalam upaya mempercepat proses penyembuhan, mempertahankan dan meningkatkan status gizi (2).

Pelayanan asuhan gizi rawat inap adalah serangkaian kegiatan yang terorganisir atau terstruktur yang memungkinkan untuk identifikasi kebutuhan gizi dan penyediaan asuhan untuk memenuhi kebutuhan tersebut.

Tahapan pelayanan gizi rawat inap diawali dengan skrining atau penapisan. Skrining gizi merupakan proses yang cepat, sederhana, efisien, mampu dilakukan, murah, tidak beresiko kepada individu yang diskrining, valid dan reliabel serta dapat dilaksanakan petugas kesehatan ruangan dan penetapan diit oleh dokter (). Alat skrining di rumah sakit antara lain: MUST (Malnutrition Universal Screening Tools); NRS 2002 (Nutritional Risk Screening); MNA (Mini Nutritional Asessment); SNAQ (Short Nutritional Asessment Quisioner); STAMP (Screening Tools Asessment of Malnutrition in Pediatric); PNI (Prognostic Nutritional Indexs) dan SGA (Subjective Global Assesment). Skrining gizi bertujuan untuk mengidentifikasi pasien yang beresiko malnutrisi, tidak beresiko malnutrisi atau kondisi khusus. Kondisi khusus yang dimaksud adalah pasien dengan kelainan metabolik, hemodialisa anak, geriatrik, dengan kemoterapi atau radiasi, luka bakar, pasien dengan imunitas, sakit kritis. Sebagian besar alat skrining terdiri dari 3 pertanyaan dasar: penurunan BB, penurunan asupan makanan, keparahan penyakit (4). Rekomendasi ESPEN (European Society For Parenteral and Enteral Nutrition), menetapkan bahwa skrining dilakukan pada awal pasien masuk rumah sakit ( 1 x 24 jam setelah pasien masuk rumah sakit) untuk mengidentifikasi pasien yang beresiko masalah gizi (5). Jika skrining gizi menunjukkan pasien yang tidak beresiko malnutrisi, maka dianjurkan skrining ulang setelah satu minggu oleh perawat, sebaliknya jika skrining gizi menunjukkan pasien beresiko sedang dilakukan skrining lanjut oleh ahli gizi. Jika beresiko pasien beresiko malnutrisi, maka dilakukan pengkajian atau assesment gizi dan dilanjutkan dengan langkah-langkah proses asuhan gizi terstandart oleh ahli gizi. Apabila hasil skrining ulang beresiko malnutrisi maka dilakukan proses asuhan gizi terstandar. Pasien sakit kritis atau kasus sulit yang beresiko gangguan gizi berat akan lebih baik ditangani secara tim. Ketepatan skrining gizi akan menghasilkan ketepatan dalam intervensi gizi sehingga dapat mencegah malnutrisi di rumah sakit dan mempercepat proses penyembuhan (6).

Menurut American Dietetic Association (ADA), PAGT adalah suatu metode pemecahan masalah yang sistematis. Dengan metode PAGT ahli gizi profesional menggunakan cara berfikir kritisnya dalam membuat keputusan untuk menangani berbagai masalah yang berkaitan dengan gizi sehingga dapat memberikan asuhan yang aman, efektif dan berkualitas tinggi. ADA merekomendasikan agar memberikan asuhan gizi dengan menggunakan PAGT (7), dalam bentuk serangkaian kegiatan yang berulang (siklus). Tahap pertama adalah asssesment gizi yang dikelompokkan dalam 5 kategori yaitu: 1) anamnesis riwayat gizi; 2) data biokimia, tes medis dan prosedur (termasuk data laboratorium); 3) pengukuran antropometri; 4) pemeriksaan fisik klinis; 5) riwayat personal. Tahap kedua adalah diagnosa gizi untuk mencari pola dan hubungan antar data yang terkumpul dan kemungkinan penyebabnya. Pada tahap selanjutnya dilakukan pemilahan masalah gizi yang spesifik dan penetapan masalah gizi secara singkat dan jelas menggunakan terminologi yang ada. Penulisan diagnosa gizi menggunakan konsep PES (Problem, Etiologi, Sign/Symptoms). Diagnosa gizi dibagi dalam 3 domain (asupan, klinis, perilaku). Langkah ketiga dalam PAGT adalah intervensi gizi yang didalamnya terdapat dua komponen intervensi gizi yaitu perencanaan intervensi dan impementasi. Langkah keempat adalah monitoring dan evaluasi gizi dilakukan untuk mengetahui respon pasien atau klien terhadap intervensi dan tingkat keberhasilannya. Tiga langkah kegiatan monitoring dan evaluasi gizi adalah monitor perkembangan, mengukur hasil dan langkah terakhir evaluasi hasil. Hasil asuhan gizi rawat inap ditulis pada formulir asuhan gizi di dokumen medik atau formulir kolaborasi dengan format ADIME (Asesment, Diagnosa, Intervensi, Monitoring, Evaluasi) (2).

Pelayanan asuhan gizi rawat inap di RSI Unisma Malang, belum berjalan optimal, hanya pada pasien dengan kondisi khusus dan pasien yang memerlukan konsultasi gizi atas permintaan dokter saja dilakukan skrining gizi. Skrining gizi dilakukan oleh ahli gizi dengan menggunakan form SGA, dengan kelebihan dapat mengidentifikasi pasien yang sudah mengalami malnutrisi atau beresiko malnutrisi pada saat masuk rumah sakit. Disisi lain SGA juga memiliki kelemahan yaitu: membutuhkan waktu lebih lama atau tidak efisien, tidak ringkas, hanya dilakukan oleh Ahli Gizi, tergantung pada nilai antropometri dan laboratorium (). Oleh karena itu perlu pemilihan metode skrining yang lebih efektif dan efisien sehingga skrining gizi dapat dilakukan pada semua pasien dan merupakan asesmen awal keperawatan.

Berdasarkan Journal of Clinical Nursing Tahun 2011, alat skrining gizi yang cepat, mudah dan cocok digunakan sesuai dengan kondisi pasien yang dirawat di rumah sakit adalah MST (Malnutrition Skrining Tools) dibandingkan dengan alat skrining lain seperti MUST, NRS 2002, MNA, SNAQ, STAMP, PNI dan SGA. Kelebihan dari alat skrining MST adalah lebih efisien (waktu 30 detik), pertanyaan lebih sederhana, nilai sensitivitas dan spesifisitas 93-95\%, nilai keandalan $90-97 \%$, tidak tergantung pada nilai antropometri dan laboratorium. Meskipun demikikan MST juga memiliki kelemahan yaitu tidak bisa diterapkan pada pasien yang mengalami kesulitan komunikasi. Di Indonesia alat skrining gizi MST sudah digunakan di rumah sakit yang sudah terakreditasi KARS Versi JCI seperti RSCM Jakarta dan RSUP Sanglah.

Proses Asuhan Gizi Terstandar di RSI Unisma Malang, belum dilakukan untuk semua pasien dengan resiko malnutrisi kategori tinggi, namun hanya dilakukan pada satu orang pasien dengan kondisi khusus dalam 1 bulan. Hal ini dikarenakan ahli gizi belum menguasai PAGT secara 
mendalam sehingga merasa kesulitan dalam penentuan matrik sehingga butuh waktu lama dalam melakukan asuhan gizi metode tersebut, selain itu format form PAGT yang digunakan di RSI Unisma Malang kurang sederhana sehingga ahli gizi merasa kesulitan dalam mengaplikasikan pengisian form PAGT di lapangan. Oleh karena itu perlu dibuat form yang berpedoman pada PAGT di Indonesia dengan format yang lebih mudah dan sederhana sehingga dapat diaplikasikan di lapangan. Dalam studi ini dilakukan kajian perbandingan efektifitas dan efisiensi pengggunaan metode skrining MST dan form PAGT sehingga dapat meningkatkan mutu pelayanan gizi yang optimal sesuai dengan Pedoman Gizi Rumah Sakit (PGRS) Tahun 2013.

\section{METODE}

Kajian diawali dengan sosialisasi yang di hadiri oleh manajer keperawatan dan seluruh kepala ruangan yang berjumlah 9 orang. Sesudah sosialisasi dilakukan uji coba penerapan form skrining gizi MST dan form PAGT selama 2 minggu di ruang rawat inap RSI Unisma Malang. Evaluasi dilakukan untuk menilai efektifitas, efisiensi dari penerapan metode skrining gizi dengan cara membandingkan persentasi cakupan pasien terskrining dengan menggunakan metode SGA dan MST sesuai dengan pasien baru yang menjalani rawat inap sebanyak 143 orang dengan kriteria. Pasien yang menjalani rawat inap harus dilakukan skrining dalam 1×24 jam.

\section{HASIL}

Subjek uji coba ini adalah semua pasien rawat inap yang MRS tanggal 4 November sampai dengan 16 November 2013. Skrining gizi awal dilakukan oleh perawat, dari hasil skrining didapatkan hasil pasien tidak beresiko malnutrisi, resiko sedang dan resiko tinggi (high risk). Untuk pasien yang beresiko tinggi malnutrisi, dilakukan PAGT (Proses Asuhan Gizi Terstandar). Tabel 1 menyajikan prosentasi pelaksanaan skrining sejak bulan September (sebelum fase uji coba) hingga November (saat uji coba) tahun 2013.

Dari Tabel 1. Diketahui persentase cakupan pasien yang terskrining di RSI Unisma Malang dengan menggunakan metode SGA (Subjective Global Assesment) pada bulan September-Oktober yaitu 9,5\% dan 18,3\% dari jumlah seluruh pasien rawat inap pada bulan tersebut. Pada bulan November ketika dilakukan uji coba dengan menggunakan metode skrining MST, jumlah pasien yang terskrining yaitu $48,3 \%$ dari jumlah seluruh pasien rawat inap. Hasil ini menunjukkan peningkatan tinggi pasien yang terskrining (2-3 kali) bila menggunakan metode MST dibandingkan SGA.

Tabel 1. Persentase cakupan pasien terskrining dengan menggunakan SGA dan MST.

\begin{tabular}{cccccc}
\hline \multirow{2}{*}{ Bulan } & \multirow{2}{*}{ Tahun } & $\begin{array}{c}\text { Metode } \\
\text { Skrining }\end{array}$ & \multicolumn{2}{c}{ Jumlah Pasien } & \multirow{2}{*}{$\%$} \\
\cline { 5 - 6 } & & MRS & Ter Skrining & \\
\hline September & 2013 & SGA & 347 & 33 & 9,5 \\
Oktober & 2013 & SGA & 349 & 64 & 18,3 \\
November * & 2013 & MST & 143 & 69 & 48,3 \\
\hline
\end{tabular}

Keterangan : *2 minggu uji coba

Dari Tabel 2. Diketahui persentase cakupan pasien yang beresiko tinggi (High Risk) dan dilakukan PAGT di RSI
Unisma Malang pada bulan September-Oktober yaitu 50\% dan $7,1 \%$ dari jumlah seluruh pasien rawat inap yang beresiko tinggi malnutrisi pada bulan tersebut. Tidak ada data penunjang pasien yang tidak beresiko (no risk), sedangkan untuk pasien berisiko sedang (medium risk) tidak diketahui karena metoda skrining SGA tidak dapat mengindentifikasi risiko sedang. Pada bulan November (2 minggu uji coba), seluruh pasien yang terskrining dan diidentifikasi berisiko tinggi dilakukan PAGT. Hasil skrining juga mengidentifikasi 47 pasien tidak beresiko malnutrisi dan dilakukan skrining ulang setelah satu minggu. Jumlah pasien yang beresiko sedang sebanyak 5 pasien dan harus dilakukan skrining lanjut oleh ahli gizi. Hasil studi ini menunjukkan bahwa dengan metode MST cakupan skrining lebih besar sehingga mendorong peningkatan cakupan penerapan PAGT pada semua kasus dengan risiko tinggi gangguan gizi.

Tabel 2. Persentase cakupan pasien yang dilakukan PAGT di RSI Unisma Malang.

\begin{tabular}{ccccccc}
\hline \multirow{2}{*}{ Bulan } & Tahun & \multicolumn{5}{c}{ Jumlah Pasien } \\
\cline { 3 - 6 } & & $\begin{array}{c}\text { No } \\
\text { Risk }\end{array}$ & $\begin{array}{c}\text { Medium } \\
\text { Risk }\end{array}$ & $\begin{array}{c}\text { High } \\
\text { Risk }\end{array}$ & PAGT & $\%$ \\
\hline September & 2013 & - & - & 2 & 1 & 50,0 \\
Oktober & 2013 & - & - & 14 & 1 & 7,1 \\
November* & 2013 & 47 & 5 & 17 & 17 & 100,0
\end{tabular}

Keterangan : *2 minggu uji coba

\section{DISKUSI}

Skrining merupakan langkah awal dari proses asuhan gizi, untuk menilai perlu atau tidaknya assesment atau pengkajian gizi lanjutan. Skrining gizi dilakukan pada semua pasien yang masuk ke rumah sakit, kecuali di perinatologi, ICU, HCU. Skrining tersebut dilakukan pada pasien anak, dewasa dan kebidanan. Proses skrining harus sederhana dan dilakukan pada assesmen awal perawat dalam waktu 1 x 24 jam.

Di RSI Unisma Malang, setelah dilakukan uji coba penggunaan metode skrining MST selama 2 minggu dengan cakupan sebesar $48,3 \%$, terjadi peningkatan persentase cakupan jumlah pasien yang terskrining sebesar $34,4 \%$ dari rata rata perbandingan penggunaan metode SGA pada bulan September dan Oktober 2013 $(13,9 \%)$. Peningkatan cakupan jumlah pasien yang terskrining sebesar $34,4 \%$ sehingga menjadi $48,3 \%$ tersebut masih dibawah target ESPEN bahwa seluruh pasien yang rawat inap harus dilakukan skrining. Hal tersebut disebabkan karena sosialisasi penggunaan form skrining MST hanya dilakukan kepada kepala ruangan dan tidak dilakukan kepada pelaksana (perawat). Selain itu waktu uji coba penerapan metode skrining MST yang cukup singkat yaitu dua minggu. Peningkatan sebesar $34,4 \%$ tersebut diperkirakan akan terus mengalami peningkatan yang berbanding lurus dengan lama penerapan dan kebiasaan menggunakan metode skrining MST di RSI Unisma Malang. Oleh karena itu perlu diadakan sosialisasi dan pelatihan kepada seluruh perawat sebagai pelaksana skrining dan dilakukan monitoring evaluasi secara berkala (terjadwal). Peningkatan cakupan skrining dengan MST dibandingkan SGA karena, skrining awal dilakukan oleh perawat dan merupakan bagian dari asesmen awal keperawatan sejalan dengan standar 
akreditasi JCI Tahun 2012. Selain itu penggunaan metode skrining MST dinilai lebih cepat (30 detik), sederhana, spesifik, dapat digunakan di hampir semua pelayanan dan tidak tergantung pada nilai antropometri serta laboratorium.

Berdasarkan Journal of Clinical Nursing Tahun 2011, alat skrining gizi yang cepat, mudah dan cocok digunakan sesuai dengan kondisi pasien yang dirawat di rumah sakit adalah MST (Malnutrition Screening Tools) dibandingkan dengan alat skrining lain seperti MUST, NRS 2002, MNA, SNAQ, STAMP, PNI dan SGA. Kelebihan dari alat skrining MST adalah lebih efisien (waktu 30 detik), pertanyaan lebih sederhana, nilai sensitivitas dan spesifisitas 93-95\%, nilai keandalan 90-97\%, tidak tergantung pada nilai antropometri dan laboratorium. Di Indonesia alat skrining gizi MST sudah digunakan di rumah sakit yang sudah terakreditasi KARS Versi JCl seperti RSCM Jakarta dan RSUP Sanglah.

American Dietetic Association (ADA), menyatakan bahwa, PAGT merupakan suatu metode pemecahan masalah yang sistematis dalam membuat keputusan untuk menangani berbagai masalah yang berkaitan dengan gizi sehingga dapat memberikan asuhan yang aman, efektif dan berkualitas tinggi. Tahap pertama assesmen gizi (antropometri, biokimia, fisik klinis, dietary), tahap kedua diagnosa gizi (problem, etiology, sign and symptom), ketiga intervensi gizi (perencanaan diet, edukasi dan konsultasi gizi), keempat adalah monitoring dan evaluasi gizi (melakukan penilaian perkembangan diet pasien, melakukan metode comstok). Hasil asuhan gizi rawat inap ditulis pada formulir asuhan gizi di dokumen medik atau

\section{DAFTAR PUSTAKA}

1. Yunancy SYF, Prawiningdyah $\mathrm{Y}$, dan Budiningsari RD. Menu Pilihan Diet Nasi yang Disajikan Berpengaruh terhadap Tingkat Kepuasan Pasien VIP di RSUD Provinsi Sulawesi Tenggara. Jurnal Gizi Klinik Indonesia. 2011; 7(3).

2. Kementrian Kesehatan Republik Indonesia. Pedoman Pelayanan Gizi Rumah Sakit. Jakarta: Kementrian Kesehatan RI; 2013.

3. Susetyowati, Hadi $H$, Hakimi $M$, dan Asdie $A H$. Pengembangan Metode Skrining Gizi Untuk Pasien Dewasa Rawat Inap. Jurnal Gizi Klinik Indonesia. 2012; 8(4).

4. Fine B. Nutritional Asessment. (Online). http://www.uic.edu/depts/mcam/nutrition/pdf/nut rition_assessment.pdf

5. Kondrup J, Allison SP, Elia M, et al. ESPEN Guidelines formulir kolaborasi dengan format ADIME(9).

Di RSI Unisma Malang, setelah dilakukan uji coba diketahui bahwa seluruh pasien yang teridentifikasi berisiko tinggi dilakukan PAGT. Hal ini karena format PAGT dibuat lebih sederhana dan mudah dilakukan serta sosialisasi penggunaan form PAGT langsung dilakukan ke semua ahli gizi sehingga ahli gizi lebih memahami penggunaan form PAGT secara menyeluruh namun tetap mengacu pada format ADIME. Sebagai perbandingan di RSSA Malang jumlah pasien yang dilakukan PAGT pada bulan Oktober 2013 sebesar 964 pasien (91,3\%) dari jumlah pasien yang terskrining dengan kategori beresiko tinggi malnutrisi (1055 pasien). Hal ini disebabkan standar operasional prosedur (SPO) dan program kerja pelayanan asuhan gizi rawat inap di RSSA Malang digunakan sebagai pedoman dalam pelaksanaan seluruh kegiatan pelayanan asuhan gizi rawat inap. Dengan penerapan pedoman tersebut dapat diketahui hasil monitoring evaluasi pelaksanaan kegiatan pelayanan asuhan gizi rawat inap sebagai dasar perbaikan pelayanan gizi rawat inap.

Setelah dilakukan uji coba selama 2 minggu penerapan metode skrining MST dan PAGT di RSI Unisma Malang, terjadi peningkatan cakupan jumlah pasien yang terskrining sebesar $34,4 \%$ dan cakupan jumlah pasien yang dilakukan PAGT sebesar $100 \%$ dari pasien yang beresiko tinggi malnutrisi. Metode skrining MST dinilai lebih cepat, sederhana dan spesifik. Format PAGT dapat dibuat lebih sederhana dan mudah dilakukan namun tetap mengacu pada format ADIME. Untuk meningkatkan implementasi perlu disusun SPO dan program kerja pelayanan asuhan gizi rawat inap di RSI Unisma Malang Tahun 2013.

for Nutrition Screning 2002. 2003; 22(4): 415-421.

6. Schenker S. Malnutrition in the UK. Nutrition Bulletin. 2001; 25(2): 87-120.

7. Suhaema. Pengaruh Penerapan Proses Asuhan Gizi Terstandar terhadap Asupan Zat Gizi, Kadar Glukosa Darah dan Lama Hari Rawat Pasien Diabetes Mellitus Type 2 di RSU Provinsi NTB. (Online) 2012. http://jurnalgiziprima. wordpress.com/2012/05/06/p engaruh-penerapan-proses-asuhan-gizi-terstandarterhadap-asupan-zat-gizi-kadar-glukosa-darah-danlama-hari-rawat-pasien-dm-tipe-2-di-rsu-provinsintb/

8. Wiryani M. Nutrisi Pada Penderita Sakit Kritis. Penyakit Dalam. 2007;8(2).

9. Wijayanti T dan Niken P. Studi Kualitatif PAGT di Ruang Rawat Inap RS. St. Elizabeth Semarang. [Tesis]. Universitas Diponegoro, Semarang. 2012. 